\title{
La unidad del ser en el antiguo pensamiento griego y en la filosofía moderna alemana
}

\section{Unity of being in ancient greek philosophy and in modern german philosophy}

\author{
JUAN A. GARCÍA \\ Universidad de Málaga
}

Recibido: 10/05/2017 Aceptado: 19/12/2017

\section{RESUMEN}

Se plantea en este artículo la recuperación de la unidad del ser formulada en el pensamiento antiguo por parte del pensamiento moderno, con las dificultades que comporta, particularmente en los temas de la trascendencia de Dios y de la libertad humana. Muy especialmente, la intersubjetividad queda lesionada en ese intento, razón por la cual la filosofía moderna no sólo es subjetivista, sino solipsista.

\section{PALABRAS CLAVE \\ UNIDAD; LIBERTAD; INTERSUBJETIVIDAD}

\section{ABSTRACT}

In this paper I propose the recovery of the unity of being formulated in ancient thought, by the modern thought, with the difficulties involved in such aim, particularly in the themes of the transcendence of God and human freedom. Moreover, intersubjectivity is injured in that attempt. For that reason, modern philosophy is not only subjectivist, but solipsistic

KEY WORDS

UNITY; FREEDOM; INTERSUBJECTIVITY 


\section{LA UNIDAD EN LA FILOSOFÍA GRIEGA}

Nos parece QUe el tema BÁsico de la filosofía griega es el de lo uno y lo múltiple: de qué manera el ser es uno, siendo muchos y distintos todos los seres; o cómo es uno, cuando los seres cambian y mudan, mostrando múltiples y variadas formas de ser. Y, ciertamente, todos los estudiosos de esa filosofía han señalado el tema de lo uno y lo múltiple como uno de los neurálgicos en el pensamiento antiguo. Por eso, aquí partimos de que el problema nuclear del pensamiento griego es la unidad.

Con todo, la unidad entera del ser, ${ }^{1}$ que -dicho sea de paso- es a la postre Dios -el pantheos-, se puede pensar -y de hecho los griegos la pensaron- de distintas maneras.

En su época más antigua, la de los filósofos presocráticos, la unidad del ser se pensó inicialmente como unicidad: la de aquello único y redondo, sugerido por Jenófanes, que impide toda multiplicidad tornándola aparente. ${ }^{2} \mathrm{Y}$ después la pensaron como la indeterminación de un principio, to apeiron, que exige -para ser justo- la mudanza y permuta entre sus diversas determinaciones. $\mathrm{O}$ también fue pensada ulteriormente como una indeterminación que ella misma se determina, o sea como la unidad numérica: que se reitera en la pluralidad de lo múltiple de un modo armónico. De modo semejante, en el pensamiento oriental hay algunos planteamientos sobre la unidad del ser comprensibles, y paralelos a éstos de los primeros filósofos griegos.

Después, ya en el período ateniense de la filosofía, se alcanzaron otras formas más depuradas de establecer la unidad de lo diverso; porque no son meras unidades pensadas por el hombre para reunir lo múltiple, sino más bien unidades que engloban la propia diversidad entre el pensamiento humano y la naturaleza de los seres. Tales son: la universalidad conceptual, que encuentra lo común a distintos particulares; la analogía judicativa que articula las diferentes y heterogéneas formas de ser; y el orden entre los diversos seres, tal que los dirige a un fin ideal, de modo que constituyan entre todos ellos un universo común.

Hasta que, por último, la unidad se entendió como la plenitud del ser, que se entiende separada de cualquiera de los entes, y se atribuye solo al primero de ellos: el unum plotiniano. El cual es previo a su multiplicación en los distintos seres, pues de él -por algún proceso de emanación o derivación- surgieron todos los demás; y además permite o constituye su reunificación posterior a

1 Cfr. GEIGER, L.B.: L'unité de l'étre. «Revue des sciences philosophiques et théologiques» París 33 (1949) 1-14.

2 Cfr. ALLEN, R.E.: Unity and infinity: Parménides. «Review of metaphysics» Washington 27 (1974) 697-725. 
partir de su distinción. El neoplatonismo representa así la culminación, la mejor comprensión de la unidad, ${ }^{3}$ dentro del pensamiento antiguo.

Al final de todo este esfuerzo pensante por establecer la unidad del ser, se termina por considerar el conjunto de lo real, la omnitud de lo ente, como un universo ordenado. Y además jerarquizado: desde el primero y superior de los seres, que constituye su plenitud, hasta el mínimo e inferior de ellos: eso es el ser, el conjunto de lo existente, para la filosofía antigua.

\section{LA ESCISIÓN DE LA UNIDAD EN EL PENSAMIENTO MEDIEVAL.}

En cambio, el pensamiento medieval -y por razones religiosas- entiendo que supuso la escisión de la unidad del ser establecida por los griegos. En el medievo, las creencias religiosas en un Dios trascendente, creador; y en la libertad y destino eterno de la persona humana, que -más allá de este mundobusca encontrarse con el creador, condujeron a la filosofía a romper la unidad de lo ente forjada por el pensamiento antiguo.

No es ya el universo el ámbito en el que se conjuntan todos los seres, del primero al último, sino que ahora todos ellos remiten a Dios como a su autor. Un Dios, no sólo considerado como el primero de los seres, sino como un ser distinto de todos ellos: eterno, trascendente respecto de todos, creador de todo y al que todo lo existente se refiere exclusivamente. Un ser eterno, al que se atribuye la unidad y plenitud del ser; del que las criaturas sólo participan limitadamente, puesto que son temporales. Además, el hombre desborda el universo. Ya que, como ser espiritual que es, se asemeja a Dios; y a él puede destinarse por encima de cualquier otra entidad mundana.

De modo que Dios, el hombre y el mundo se han escindido por mor de la inspiración religiosa del pensamiento medieval. De acuerdo con esta escisión, el problema de la filosofía medieval no es ya la unidad del ser, sino precisamente la distinción entre los seres. Ante todo, la distinción entre el creador y las criaturas; y luego, la distinción entre las criaturas materiales y las espirituales.

Primeramente, los pensadores medievales tuvieron interés en distinguir al creador de las criaturas. El Dios de la fe religiosa es muy superior al Dios en que pensaron los griegos. ${ }^{4}$ Es trascendente, es decir, no sólo es el primero de los seres del universo, sino que está fuera de él y es superior a cuanto en el universo ocurre. Es un Dios eterno, separado y creador, del que todo depende; y no sólo un principio interno al universo, motor de los dinamismos entre los seres o generador de su pluralidad.

Esta trascendencia de la divinidad se propuso básicamente de dos maneras distintas: distinguiendo en las criaturas la esencia de la existencia, como hizo

3 Cfr. SINGEVIN, Ch.: Essai sur l'un. Du Seuil, París 1969.

4 Cfr. BECK, H.: El Dios de los sabios y de los pensadores. Gredos, Madrid 1968. 
Tomás de Aquino, y reservando la identidad entre ambas para el creador; o bien, como lo hizo Duns Scotto, distinguiendo el ser infinito de Dios, respecto de todos los demás, que son seres finitos.

Y después, en un segundo lugar, los pensadores medievales quisieron distinguir además el ser espiritual del material; precisamente, porque los seres espirituales se orientan hacia ese Dios trascendente, por encima de las realidades finitas del mundo.

La noción de persona, ${ }^{5}$ en efecto, aun teniendo conocidos antecedentes en el pensamiento antiguo (concretamente, los personajes del teatro griego y la personalidad jurídica del derecho romano) es, como se suele reconocer, una noción aportada a la filosofía por la religión cristiana: porque la creencia cristiana afirma que en la naturaleza divina, la del único Dios, se distinguen tres personas; y en cambio que, en una sola persona, la de Jesucristo, se integran dos naturalezas: la divina y la humana.

A esta distinción entre persona y naturaleza acuden los filósofos medievales; pero, concretamente, para incluir la naturaleza en los dominios de la filosofía, y sin embargo reservar la persona como tema propio de la teología religiosa. Así lo formuló Tomás de Aquino en su libro In Boetium de Trinitate, ${ }^{6}$ al distinguir seres que son sólo principios respecto de los seres que además tienen alguna esencia.?

Y así lo formuló también Duns Scotto al señalar que el objeto de la metafísica general u ontología es la naturaleza de los seres, su entidad: el ente tomado unívocamente, prescindiendo de cualquier analogía; y después, al intentar compensar esta reducción temática admitiendo como metafísicas especiales la cosmología, la psicología y la teología. Es decir, reconociendo que los seres personales no son objetos propios del saber metafísico; sino que, todo lo más, dan para una especialización peculiar de la ciencia general acerca del ser.

La división escotista de la metafísica en ontología general y sus especialidades pervive en la edad moderna. Por lo menos, temáticamente, en la división de las tres sustancias cartesianas: res cogitans, extensa e infinita. Y luego, recibida concretamente a través del racionalismo de Wolff, en los tres ideales kantianos de la razón: Dios, alma y mundo. Cuyo uso lógico es sólo regulativo; pero ilegítimo su uso puro: por lo que cosmología, psicología y teología carecen de carácter científico.

5 Cfr. SPAEMANN, R.: Personas. Eunsa, Pamplona 2000.

6 Q. 5, art. 4.

7 Cfr. SANGUINETI, J.J.: Unidad humana y unidad del cosmos. «Anuario filosófico» XVI-2 (1983) 159-68. 


\section{LA RECUPERACIÓN DE LA UNIDAD EN LA FILOSOFÍA MODERNA.}

La tarea de la filosofía moderna, ante esta ruptura medieval de la unidad del ser, nos parece que, de hecho, ha sido su recuperación: la reposición de la unidad. En efecto, bajo el conocido tópico de la comunicación de las sustancias, un problema que la filosofía cartesiana dejó abierto para la posteridad que le continuó, se oculta el tema de la unidad de lo diverso, ${ }^{8}$ que ahora se intenta recuperar.

Bien entendido: desde el renacimiento, ya no se aspira a una unidad de simplicidad, como aquélla del uno neoplatónico, o de la identidad tomista del ser y su esencia; sino que, para recuperar la unidad fragmentada en el medioevo, se propone alternativamente un modelo de unidad sincrética, o sintética. Objetivo que lo fue, especialmente, del Cusano (con su famosa coincidentia oppositorum $)^{9}$ y de Giordano Bruno: la unidad de composición frente a la unidad de simplicidad. El universal concretado de la dialéctica hegeliana es, también, el resultado de la síntesis de los contrarios.

En esta moderna recuperación de la unidad destacan especialmente Spinoza (que afirma la existencia de una sola sustancia, con diversos -y hasta infinitosatributos y modos), Schelling (que propone un Dios absoluto, cuya obra de arte son el mundo y el hombre; pues al crear Dios se expresa artísticamente en la naturaleza y en la historia) y por último Hegel: quien propuso un sujeto absoluto, que alcanza finalmente a conocerse a sí mismo: noesis noeseos, como lo dice al final de su Enciclopedia de las ciencias filosóficas. Es decir, un sujeto tal que se reconoce enteramente tras la génesis de sus propias determinaciones; y aún después, tras su alienación en la naturaleza y por mediación del espíritu. También Leibniz, aun declarado pluralista, con su doctrina del principio de razón suficiente mantiene la preeminencia de la unidad, al menos de la unidad de la racionalidad de la acción creadora.

IV. LOS PROBLEMAS DE LA REPOSICIÓN MODERNA DE LA UNIDAD.

Pero esta reposición moderna de la unidad del ser, cuando ya se habían establecido con alguna nitidez distinciones irreductibles, resulta un tanto problemática.

a) El primer problema de esta recuperación moderna de la unidad del ser es que, según observa con razón Polo, desde un enfoque creacionista, Dios $y$ la criatura son una suma imposible: ${ }^{10}$ nada añade la criatura a Dios, puesto que Dios es la plenitud entera y completa del ser, su iden-

8 Cfr. PÉREZ ALCOCER, A.: Unidad y distinción. Porrúa, México 1966.

9 Cfr. Docta ignorantia, lib. $1^{\circ}$, cap. 22.

10 No existe ningún sentido posible de totalidad en el que Dios y la criatura sean factores: Presente y futuro del hombre. Rialp, Madrid 2012²; p. 133. 
tidad real y originaria. El maestro Eckahrt, a fines de la edad media, lo señaló también afirmando que, siendo Dios puritas essendi, a su lado omnes criaturae sunt unum purum nihil. ${ }^{11}$ En sentido inverso, el monismo hegeliano contrapone el verdadero infinito al falso, al que se distingue de lo finito y se opone a él: porque el verdadero infinito es la suma, la unidad, de lo infinito y lo finito. ${ }^{12}$

b)Pero, si la unidad del ser hace difícil la distinción Dios-criatura, o es insuficiente para establecerla, aún torna más difícil entender la libertad de la persona humana. Este afán moderno por recuperar la unidad del ser perdida desde antiguo, afecta aún más negativamente al segundo tema que propició la ruptura medieval de esa unidad, esto es, a la diferencia entre el ser natural y el espiritual. ${ }^{13}$ Porque a la persona, como ser libre, no le conviene la unidad, el monismo, sino la pluralidad y la diversidad: ya que lo personal -ésta es la clave- es siempre interpersonal.

La noción de subjetividad con que se intentó pensar el ser personal a partir del nominalismo tardomedieval (desplegada en la modernidad según la trayectoria que atraviesa al sujeto psicológico, trascendental, absoluto, ${ }^{14} \mathrm{y}$ finalmente finito, sujeto en-el-mundo) supone una subordinación de la persona a la unidad. En la historia humana acontece la que Hegel llamó transformación de la sustancia en sujeto, mutación supuesta anteriormente en la noción leibniziana de mónada; en esa transformación, el sujeto pide su reconocimiento en el objeto: para evitar la que el propio Hegel llamó conciencia desgarrada. Pero la unidad de la subjetividad consigo misma se articula mal con el ser personal, por cuanto - como decimos- lo personal es siempre interpersonal: precisamente no algo unitario, acabado y cerrado en sí mismo, sino alguien que reclama multiplicidad, alteridad, réplica. A la conciencia que se reconoce aún le falta el reconocimiento ajeno.

\section{LA PRIMACÍA DEL SER PERSONAL.}

Sucede que, de los dos motivos usados por los filósofos medievales para romper la unidad del ser propia del pensamiento antiguo, el tema de la persona, es decir, la diferencia entre el ser personal y el natural, es más radical y decisivo que el de distinguir a Dios respecto de las criaturas; por mucho que inicial y

11 Sermo germ. 40 (Pfeiffer II, 136). Está en la 26ª proposición condenada por el papa Juan XXII.

12 Cfr. Ciencia de la lógica (trad. Mondolfo). Hachette, Buenos Aires 1968; p. 133.

13 Cfr. ANTONELLI, M.T.: L'unitá trascendentale dell'essere e la problemática interna dell'activitá spirituale. VV. AA.: «Actes du XI Congres International du Philosophie», Amsterdam 1955; v. III, pp. 150-6.

14 Cfr. COLOMER, E.: «Introducción» a El pensamiento alemán de Kant a Heidegger. Herder, Barcelona 1986; v. I, pp. 13-23. 
aparentemente esta posición sorprenda a una mente con creencias religiosas, aquéllas de las que partió la ruptura medieval de la unidad del ser.

De hecho, ya en el pensamiento antiguo se cuestionó si se daba a partir del ser primero una emanación necesaria de los seres derivados, es decir, si éstos proceden de aquél por naturaleza; o bien una creación libre de ellos, tal y como sugirió el judío Filón de Alejandría: las criaturas proceden del creador no por naturaleza, sino por voluntad. En la idea de una creación libre la libertad no significa simplemente contingencia: aquello que es posible que ocurra, o bien que no suceda; sino que la libertad apela a un actuar personal: que, como siempre es interpersonal, exige ser dirigido a un destinatario; crear es dar el ser a alguien. El dilema entre emanación y creación, que separa el pensamiento antiguo del medieval, no sólo alude -por tanto- a la diversidad criatura-creador; sino -tanto como ello y quizá antes- a la diferencia entre el ser natural y el ser libre, personal.

La explicación última que podemos ofrecer de la superioridad del tema de la persona sobre el de la distinción criatura-creador, como justificación medular de la ruptura de la unidad del ser en el medievo, no está -con todo- en el hecho de que Dios también sea persona: autor libre de la creación y no principio natural de la emanación. Sino en que la atención a la persona comporta el añadido de la dimensión metódica del saber sobre su dimensión temática; y el asunto del método es ciertamente la cuestión definitoria del pensamiento moderno.

Quizá temáticamente, la superioridad de Dios sobre toda criatura sea lo primero y primordial, especialmente para una mentalidad religiosa: Dios -a diferencia de toda criatura- es la identidad del ser, o el ser infinito. Pero esto será cierto siempre que haya alguien capaz de conocerlo, esto es, de saber y entender eso. Es decir, esa prioridad será relevante siempre que haya alguien para el que tal cosa tenga algún significado, esto es, para un espíritu: para un ser libre, que es el que hace la metafísica y conoce tan importante distinción. Aquí aparece, entonces, la cuestión metódica: el conocimiento de la distinción criatura-creador. En definitiva, es la persona el referente de la distinción criatura-creador: porque la trascendencia del ser supremo a quien afecta e interpela es a la libertad humana.

Ser sólo criatura es algo muy notable, ciertamente; pero más sobresaliente -en especial- para un ser libre, dueño de su conducta. Por eso, la distinción real no es sólo una doctrina metafísica, que afecta a todas las criaturas; sino una distinción particularmente importante en antropología.

\section{DiOS Y LA LIBERTAD HUMANA.}

Quizá se aprecie mejor esta primacía del ser personal a la hora de romper la unidad del ser si consideramos que la primera reacción ante la separación del pensamiento humano respecto de la realidad que supuso la ruptura medieval de 
la unidad del ser, y en concreto el descubrimiento de la subjetividad individual, fue el argumento ontológico anselmiano. ${ }^{15}$

Pensar y ser serán algo distinto, quizás, de acuerdo con las posiciones señaladas en la conocida como polémica de los universales (precisamente Anselmo escribió contra Roscelino); pero eso ocurrirá, en todo caso, excepto si pensamos en Dios, cuya sola idea exige su existencia: el hombre está como obligado a pensar que Dios existe.

Tal y como había señalado ya Avicena, considerando esencia y existencia como principios -aunque sólo sea- lógicamente distintos, Dios es el ser necesario: aquella esencia a la que pertenece de suyo la existencia.

$\mathrm{Y}$, justamente por esta razón que estamos glosando, el argumento ontológico, que es el argumento para demostrar la existencia de Dios característicamente moderno -aunque se formule inicialmente en la baja edad media-, pervive durante toda la modernidad.

Hasta que al hombre se le ocurre pensar que Dios ha muerto, como lo enunció Nietzsche; ${ }^{16}$ y que hemos sido nosotros los que lo hemos matado. También Dios está, por consiguiente, bajo el ámbito de la libertad humana.

Y nos permitimos comentar: ¡qué cosa más lógica! Eso es precisamente lo que estamos sugiriendo aquí: que, desde el primado metódico del ser personal, por escapar éste del monismo -de la unicidad-, Dios es -con todo rigor- tema, referente y correlato de la libertad humana: que puede afirmarlo o negarlo, reconocerlo u oponerse a él.

Si la distinción del ser personal respecto del natural está por encima, al menos metódicamente, de la distinción entre el creador y las criaturas, el tema de la unidad del ser tiene que pasar a un segundo plano: no puede ser ya el problema primordial; porque a la persona no le conviene la unidad, sino la multiplicidad, si toda persona lo es con otra, si no cabe persona única (la idea de persona única es un absurdo). ${ }^{17}$

Por esto, la reposición moderna de la vieja unidad del ser ahora perdida es una pretensión desajustada; y la idea moderna de la subjetividad nos ha abocado a un callejón sin salida, que llega hasta la disolución del sujeto en algunos planteamientos filosóficos del siglo XX.

VII. EL TEMA DE LA PERSONA Y SUS INDICIOS EN LA FILOSOFÍA HEGELIANA.

En orden a la persona el tema de la unidad tiene que pasar a un segundo plano y no puede ser el problema primordial, porque a la persona no le corres-

15 Cfr. Proslogion c. II y c. XV.

16 Cfr. Así habló Zaratustra 4 a parte: «Del hombre superior».

17 POLO, L.: Antropología trascendental. Edición de las obras completas. Eunsa, Pamplona 2016; p. 163. 
ponde unidad, sino más bien multiplicidad: lo personal, como estamos diciendo, es siempre interpersonal. La autocomprensión del hombre como subjetividad se queda en este punto muy corta, es parcial y -a la postre- negativa.

Lo que se aprecia ya, aunque sea sólo hasta cierto punto, en la filosofía de Hegel: en su convicción de que toda conciencia exige dúplica, ${ }^{18}$ una señal inequívoca del ser personal.

Pero, sobre todo, se aprecia en la oscilación latente en el sistema hegeliano entre la necesidad de la dialéctica que genera los contenidos y la libertad propia de la idea absoluta que pierde su soledad cuando se contempla en ellos; por tanto, no el comienzo elemental y vacío, sino el reconocimiento final en la plenitud del saber. La libertad del sujeto absoluto es el conocimiento de la necesidad, dice Hegel glosando a Spinoza (que, por lo demás, repite a Demócrito); dejar de contemplarla y alienarse, no pasa de ser más que una arbitrariedad: una distracción completamente irracional, para Hegel, como denunció singularmente Schelling. ${ }^{19}$

Y, finalmente, un tercer vestigio en el pensamiento hegeliano de que la problemática del ser personal está latente bajo su prevalente y lógico deseo de unidad absoluta es la consecuencia de esa irracionalidad antedicha, completamente impersonal. Se aprecia claramente en la comparación de su sistema con el neoplatónico: ${ }^{20}$ la cual arroja llamativamente como balance la exclusividad del retorno epistrófico, frente a la salida proódica. La alienación hegeliana anula esta última, dejando para el espíritu sólo aquél primero: el afán de reconocimiento es el impulso del trabajo del negativo en la historia. Paralelamente, Hegel no acierta a ver la alienación en términos -aunque fuera- lejanamente personales, es decir, de generosidad, de donación interpersonal. La confusión hegeliana de inteligencia y voluntad, muy propia de todo el pensamiento moderno, pasa aquí ya su factura.

VIII. CONCLUSIÓN: LA SOLUCIÓN PERSONALISTA DEL PROBLEMA.

Pues bien: si, como han señalado Hegel y Polo (la noción de persona única es completamente incoherente), ${ }^{21}$ la persona exige dualidad, entonces la reunificación del ser según la mente griega, es una tarea desviada e inconveniente: un anacronismo perturbador e injustificable. Recuperar Grecia en Alemania,

18 Fenomenología del espíritu IV, B, 2: la duplicación de la autoconciencia es esencial en el concepto del espíritu.

19 Cfr. Lecciones muniquesas para la historia de la filosofía moderna. Edinford, Málaga 1993; p. 242.

20 Polo sugiere esta comparación en Hegel y el posthegelianismo. Eunsa, Pamplona 19992; pp. 33 ss.

21 «El descubrimiento de Dios desde el hombre». Studia poliana, Pamplona 1 (1999) 20. 
objetivo muy hegeliano, ${ }^{22}$ está - por este motivo- fuera de lugar: la noción de sujeto no es adecuada para el ser personal.

La ruptura con la tradición medieval para recuperar a Grecia; ruptura que también es objetivo de Descartes y de la ilustración, por su subjetivismo y la deseada autonomía de la razón, es -a la vista de esto que decimos- un despropósito arcaizante, que no aprovecha los factores que propiciaron esa ruptura: en particular, la originalidad y peculiaridad del ser personal.

A la postre, el solipsismo a que aboca el subjetivismo de la moderna actitud trascendental, indiscutiblemente manifiesto -un siglo después- en la quinta de las Meditaciones cartesianas de Husserl, ${ }^{23}$ es un síntoma patente del desvarío.

Frente a él, la filosofía dialógica del pensamiento judío contemporáneo (el yo-tú de Buber, o el yo-otro de Levinas) es una llamada de atención muy seria: una persona única es absurda. Como ellos mismos dicen, Jerusalén frente a Atenas; o -como habría que decir aquí- Jerusalén frente a Jena.

Pero, como el personalismo contemporáneo, y el pensamiento judío desde Rosenkranz, es algo alérgico a la metafísica, la presentación histórica de su temática que aquí hemos intentado esbozar tiende a enraizar éstas sus últimas consideraciones con la tradición de la historia del pensamiento y sus problemáticas; tal que nos permita enlazar sus actuales preocupaciones y soluciones, que -por lo demás- son también las nuestras, con su génesis histórico-filosófica, esto es, la que las enlaza con la tradición.

Juan A. García es Catedrático de Filosofía en la Universidad de Málaga.

Lineas de investigación

Teoría del conocimiento, Metafísica, Historia de la Filosofía

Últimas publicaciones:

Presente y libertad. Universidad de Navarra, Pamplona 2015

El Nietzsche de Polo, la luz y la persona. "Estudios filosóficos polianos" san Juan (Argentina) 4 (2017) 33-44.

Kant contra Leibniz: los límites de la razón. ESCRIBANO-SÁNCHEZ (eds.): “Leibniz en diálogo" Themata, Sevilla 2017; pp. 233-41.

Email: jagarciago@uma.es

22 Cfr. POLO, L.: Estudios de filosofía moderna y contemporánea. Edición de las obras completas. Eunsa, Pamplona 2015; c. VI: «Introducción a Hegel»; pp. 150 ss.

23 Cfr. § 50. 